\title{
Comparison of neural substrates of temporal discounting between youth with autism spectrum disorder and with obsessive-compulsive disorder
}

\author{
C. O. Carlisi ${ }^{1 *}$ t, L. Norman $^{1}$ t, C. M. Murphy ${ }^{1,2,3}$, A. Christakou ${ }^{4}$, K. Chantiluke $^{1}$, V. Giampietro ${ }^{5}$, \\ A. Simmons ${ }^{5,6,7}$, M. Brammer ${ }^{5}$, D. G. Murphy ${ }^{2,3}$, MRC AIMS consortium $\ddagger$, D. Mataix-Cols ${ }^{8}$ and \\ K. Rubia ${ }^{1}$ \\ ${ }^{1}$ Department of Child and Adolescent Psychiatry, Institute of Psychiatry, Psychology and Neuroscience, King's College, London, UK \\ ${ }^{2}$ Department of Forensic and Neurodevelopmental Sciences, Sackler Institute for Translational Neurodevelopmental Sciences, Institute of Psychiatry, \\ Psychology and Neuroscience, King's College, London, UK \\ ${ }^{3}$ Behavioural Genetics Clinic, Adult Autism Service, Behavioural and Developmental Psychiatry Clinical Academic Group, South London and \\ Maudsley Foundation NHS Trust, London, UK \\ ${ }^{4}$ Centre for Integrative Neuroscience and Neurodynamics, School of Psychology and Clinical Language Sciences, University of Reading, Reading, UK \\ ${ }^{5}$ Department of Neuroimaging, Institute of Psychiatry, Psychology and Neuroscience, King's College, London, UK \\ ${ }^{6}$ National Institute for Health Research (NIHR) Biomedical Research Centre (BRC) for Mental Health at South London and Maudsley NHS \\ Foundation Trust and Institute of Psychiatry, Psychology \& Neuroscience, King's College London, London, UK \\ ${ }^{7}$ Department of Neurobiology, Care Sciences and Society, Center for Alzheimer Research, Division of Clinical Geriatrics, Karolinska Institutet, \\ Stockholm, Sweden \\ ${ }^{8}$ Department of Clinical Neuroscience, Centre for Psychiatry Research, Karolinska Institutet, Stockholm, Sweden
}

Background. Autism spectrum disorder (ASD) and obsessive-compulsive disorder (OCD) share abnormalities in hot executive functions such as reward-based decision-making, as measured in the temporal discounting task (TD). No studies, however, have directly compared these disorders to investigate common/distinct neural profiles underlying such abnormalities. We wanted to test whether reward-based decision-making is a shared transdiagnostic feature of both disorders with similar neurofunctional substrates or whether it is a shared phenotype with disorder-differential neurofunctional underpinnings.

Methods. Age and IQ-matched boys with ASD $(N=20)$, with OCD $(N=20)$ and 20 healthy controls, performed an individually-adjusted functional magnetic resonance imaging (fMRI) TD task. Brain activation and performance were compared between groups.

Results. Boys with ASD showed greater choice-impulsivity than OCD and control boys. Whole-brain between-group comparison revealed shared reductions in ASD and OCD relative to control boys for delayed-immediate choices in right ventromedial/lateral orbitofrontal cortex extending into medial/inferior prefrontal cortex, and in cerebellum, posterior cingulate and precuneus. For immediate-delayed choices, patients relative to controls showed reduced activation in anterior cingulate/ ventromedial prefrontal cortex reaching into left caudate, which, at a trend level, was more decreased in ASD than OCD patients, and in bilateral temporal and inferior parietal regions.

Conclusions. This first fMRI comparison between youth with ASD and with OCD, using a reward-based decision-making task, shows predominantly shared neurofunctional abnormalities during TD in key ventromedial, orbital- and inferior fronto-striatal, temporo-parietal and cerebellar regions of temporal foresight and reward processing, suggesting trans-diagnostic neurofunctional deficits.

Received 14 September 2016; Revised 10 March 2017; Accepted 29 March 2017; First published online 24 April 2017

Key words: ASD, fMRI, OCD, temporal discounting.

\footnotetext{
* Address for correspondence: C. Carlisi, BA, Department of Child and Adolescent Psychiatry/MRC Social, Genetic and Developmental Psychiatry (SGDP) Centre, Institute of Psychiatry, Psychology and Neuroscience, King's College London, 16 DeCrespigny Park, London, SE5 8AF, UK.

(Email: carlisi.christina@gmail.com)

+ CC and LN contributed equally to this work.

‡ The MRC AIMS Consortium is a collaboration of Autism research centres in the UK including the Institute of Psychiatry, Psychology \& Neuroscience. London, the Autism Research Centre, University of Cambridge, and the Autism Research Group, University of Oxford. It is funded by the MRC UK and headed by the Department of Forensic and Developmental Sciences, Institute of Psychiatry, Psychology \& Neuroscience. The Consortium members are in alphabetical order: Bailey A.J., Baron-Cohen S., Bolton P.F., Bullmore E.T., Carrington S., Chakrabarti B., Daly E.M., Deoni S.C., Ecker C,. Happe F., Henty J., Jezzard P., Johnston P., Jones D.K., Lombardo M., Madden A., Mullins D., Murphy C.M., Murphy D.G., Pasco G., Sadek S., Spain D., Steward R., Suckling J., Wheelwright S., Williams S.C.
}

This is an Open Access article, distributed under the terms of the Creative Commons Attribution licence (http://creativecommons.org/licenses/by/4.0/), which permits unrestricted re-use, distribution, and reproduction in any medium, provided the original work is properly cited. 


\section{Introduction}

Autism Spectrum Disorder (ASD) is characterized by social communication difficulties and stereotyped repetitive behaviours (American Psychiatric Association, 2013) with a prevalence of $0.6-2 \%$, predominantly in males (Blumberg et al. 2013). Obsessive-Compulsive Disorder (OCD) involves recurrent, intrusive and distressing thoughts (obsessions) and repetitive rituals (compulsions) (American Psychiatric Association, 2013), affecting $1-3 \%$ of the population with a higher male prevalence in children (Ruscio et al. 2010). These disorders are highly comorbid, with rates exceeding 30\% (Simonoff et al. 2008) and can sometimes be clinically difficult to separate (Doshi-Velez et al. 2014).

The allowance of co-diagnosis of OCD with ASD in DSM-5 questions whether phenotypes common to both disorders are mediated by shared or disorderspecific mechanisms. Characteristic behaviours observed in ASD are wide-ranging and heterogeneous but can include physical rocking, tapping, counting and behavioural inflexibility (e.g. insistence on performing actions in a certain order). Similarly, behaviours in OCD vary widely, but compulsions often include hand-washing, checking, and, sometimes seemingly similar to ASD, counting and behavioural inflexibility surrounding order and symmetry. It has been hypothesized that in both cases, these behaviours may relate to abnormalities in fronto-striatal circuitry that is also important in reward-based decisionmaking (Langen et al. 2011). In ASD, repetitive behaviours are often considered soothing and rewarding, while in $\mathrm{OCD}$, compulsions are performed to reduce anxiety and are often debilitating. However, despite this distinction, converging evidence suggests repetitive behaviours in ASD and OCD may be mediated by shared mechanisms including behavioural disinhibition or motivation control (Hollander et al. 2007). Such impairments may maintain diminished control over repetitive behaviours in ASD and compulsions in OCD and involve goal-directed reward-based decision-making. A meta-analysis of structural and functional neuroimaging studies comparing ASD and OCD found shared reduced structure and function during cognitive control in medial prefrontal regions but that OCD had disorder-specific increased function and structure in basal ganglia and insula while ASD had disorder-specific functional reduction in DLPFC and reduced PCC deactivation, presumably reflecting disorder-specific fronto-striato-insular dysregulation in OCD but fronto-striato-insular maldevelopment in ASD, both underpinned by shared reduced prefrontal control (Carlisi et al. 2016b).

Both disorders also share deficits in motivated 'hot' executive functions (EF) (Zelazo \& Müller,
2007) including reward-based decision-making measured by choice-impulsivity tasks of gambling and temporal discounting (TD) (Hill, 2004; Sanders et al. 2008; Abramovitch et al. 2013; Chen et al. 2016). TD requires choosing between small immediate rewards and larger later rewards, assessing the extent to which a reward is subjectively discounted when delayed in time (Rubia et al. 2009). The ability to inhibit immediate reward choices and wait for larger rewards depends on well-developed frontal lobemediated motivation control and temporal foresight and is a key for mature decision-making. A TD function is typically hyperbolic, with steeper rates reflecting more impulsive choice behaviour (Richards et al. 1999) (see online Supplement). TD matures with age (Christakou et al. 2011; Steinbeis et al. 2016) and varies among individuals (Odum, 2011), with steeper TD observed in younger people and individuals with attention deficit hyperactivity disorder (ADHD) and related impulsive disorders (Rubia et al. 2009; Noreika et al. 2013). Functional magnetic resonance imaging (fMRI) studies of TD in healthy adults and children implicate ventromedial-fronto-limbic networks of reward-based decision-making and dorsolateral and inferior-fronto-insula-striato-parietal networks of temporal foresight (Christakou et al. 2011; Chantiluke et al. 2014b; Wesley \& Bickel, 2014).

People with ASD have been shown to have deficits in reward-motivated and forward-thinking behaviour including reward processing and reversal learning (Scott-Van Zeeland et al. 2010; Chantiluke et al. 2015a), incentive processing (Dichter et al. 2012), planning (Ozonoff \& Jensen, 1999; Geurts et al. 2004; Hill, 2004) and TD (Chantiluke et al. 2014b). However, there have also been negative findings (Antrop et al. 2006; Demurie et al. 2013). ASD is characterized by fronto-temporo-limbic abnormalities mediating socioemotional processes (Via et al. 2011; Philip et al. 2012; Carlisi et al. 2016b), and in ventromedial/fronto-limbic brain regions involved in TD (Christakou et al. 2011; Peters \& Büchel, 2011) during reward-related and planning tasks (Just et al. 2007; Schmitz et al. 2008; Dichter et al. 2012; Kohls et al. 2013). However, only one fMRI study has been published investigating the neural correlates of TD in adolescents with ASD, which found a weaker relationship between task-performance and bilateral superior temporal and right insular activation relative to controls (Chantiluke et al. 2014b).

Patients with OCD show deficits during planning (van den Heuvel et al. 2011; Shin et al. 2014), goaldirected learning (Gillan \& Robbins, 2014; Voon et al. 2015), reward-based decision-making, gambling (Grassi et al. 2015; Figee et al. 2016), and incentive processing (Figee et al. 2011). Despite evidence that heightened impulsivity is a phenotype associated with OCD 
(Benatti et al. 2014), only one (Sohn et al. 2014) of three TD studies in OCD (Vloet et al. 2010; Pinto et al. 2014; Sohn et al. 2014) found performance deficits.

Neuroimaging studies show that OCD is characterized by structural and functional abnormalities in medial and orbitofronto-striato-thalamo-cortical networks mediating EF (Menzies et al. 2008; Radua et al. 2010; Carlisi et al. 2016b; Norman et al. 2016). No fMRI studies, however, have investigated TD in OCD. Studies using other decision-making tasks in OCD have found hyperactivity in ventral-affective regions including ventromedial prefrontal, orbitofrontal and rostral anterior cingulate cortex (rACC) projecting to ventral striatum and mediodorsal thalamus, and hypoactivity in dorsalcognitive cortico-striato-thalamic regions including dorsolateral prefrontal (DLPFC), temporal and parietal association cortex projecting to the dorsal striatum and caudate in patients relative to controls (Menzies et al. 2008; Brem et al. 2012). Hypoactivation in DLPFC and caudate has furthermore been shown in OCD patients during planning (van den Heuvel et al. 2005, 2011).

This suggests that ASD and OCD have abnormalities during planning and 'hot' EF tasks including rewardbased decision-making, and that this may be underpinned by ventromedial and dorsolateral prefrontostriato-limbic abnormalities. However, it is unclear whether reward-based decision-making problems in both disorders are underpinned by shared transdiagnostic mechanisms or by disorder-specific underlying abnormalities.

We hypothesized that adolescents with ASD would be more impaired on TD relative to adolescents with OCD and controls (Scott-Van Zeeland et al. 2010; Chantiluke et al. 2014b; Chen et al. 2016) and that both clinical groups compared with healthy controls would show underactivation in underlying ventromedial prefrontal, limbic and striatal regions mediating TD (Fineberg et al. 2009), reflecting a trans-diagnostic neurofunctional phenotype (Chantiluke et al. 2015a; Grassi et al. 2015; Chen et al. 2016). However, we hypothesized that people with OCD would show disorder-specific (ventro)medial and dorsolateral-prefrontal dysfunction (Menzies et al. 2008; Carlisi et al. 2016b; Norman et al. 2016) while ASD adolescents would show disorderspecific insular and temporo-parietal dysfunction compared to controls (Di Martino et al. 2009; Chantiluke et al. 2014b; Carlisi et al. 2016b).

\section{Methods}

\section{Participants}

Sixty-nine right-handed (Oldfield, 1971) boys (20 controls, 29 boys with ASD, 20 boys with OCD), 11-17 years, $\mathrm{IQ} \geqslant 70$ (Wechsler, 1999) participated. Medication- naïve boys with high-functioning ASD were recruited from local clinics and support-groups. ASD diagnosis was made by a consultant psychiatrist using ICD-10 research diagnostic criteria (WHO, 1992) and confirmed with the Autism Diagnostic Interview-Revised [ADI-R; (Lord et al. 1994)]. The ADI-R and the Autism Diagnostic Observation Schedule [ADOS; (Lord et al. 2000)] were completed for all ASD boys; all 29 reached autism cut-offs on all ADI-R (social/communication/ restricted/stereotyped) and ADOS (communication/ social) domains. ASD participants either fulfilled ICD-10 research diagnostic criteria for autism $(N=7)$ or fulfilled these criteria but had no history of language delay and therefore were subtyped with Asperger's syndrome $(N$ =22). Parents of ASD boys completed the Social Communication Questionnaire [SCQ; (Rutter et al. 2003)] and the Strengths and Difficulties Questionnaire [SDQ (Goodman \& Scott, 1999)] (see online Supplement). ASD participants had a physical examination to exclude comorbid medical disorders and biochemical, haematological and chromosomal abnormalities associated with ASD. None of the ASD individuals had a comorbid diagnosis of OCD or any psychiatric disorder, and none of the OCD patients had comorbid ASD.

OCD boys were recruited from National and Specialist OCD clinics. Diagnosis was made by a consultant psychiatrist using ICD-10 criteria and confirmed by the Children's Yale-Brown Obsessive-Compulsive Scale [CY-BOCS; (Goodman et al. 1989)]. Parents of OCD patients completed the SDQ. Patients with comorbid psychiatric or neurological disorders, including ASD, were not included in the OCD sample, although OCD patients were not specifically assessed for ASD. Four boys were prescribed stable doses of antidepressants (see online Supplement).

Twenty age and handedness-matched healthy controls were recruited locally by advertisement. Controls scored below clinical threshold on the SDQ and SCQ for any disorder and did not have any psychiatric condition.

Exclusion criteria for all participants included comorbid psychiatric or medical disorders affecting brain development (e.g. epilepsy/psychosis), drug/ alcohol dependency, head injury, genetic conditions associated with ASD, abnormal structural brain scan and MRI contraindications. All controls also participated in previously published studies testing fluoxetine effects on TD in ADHD (Carlisi et al. 2016a) and neurofunctional maturation of TD in healthy adults and adolescents (Christakou et al. 2011); all but four ASD boys participated in our fMRI TD study comparing ASD and ADHD (Chantiluke et al. 2014b). Most ASD and control participants also participated in other fMRI tasks during their visit, published elsewhere (Christakou et al. 2013a, 2013b; Chantiluke et al. 2014a, 2015a, b; Murphy et al. 2014). 


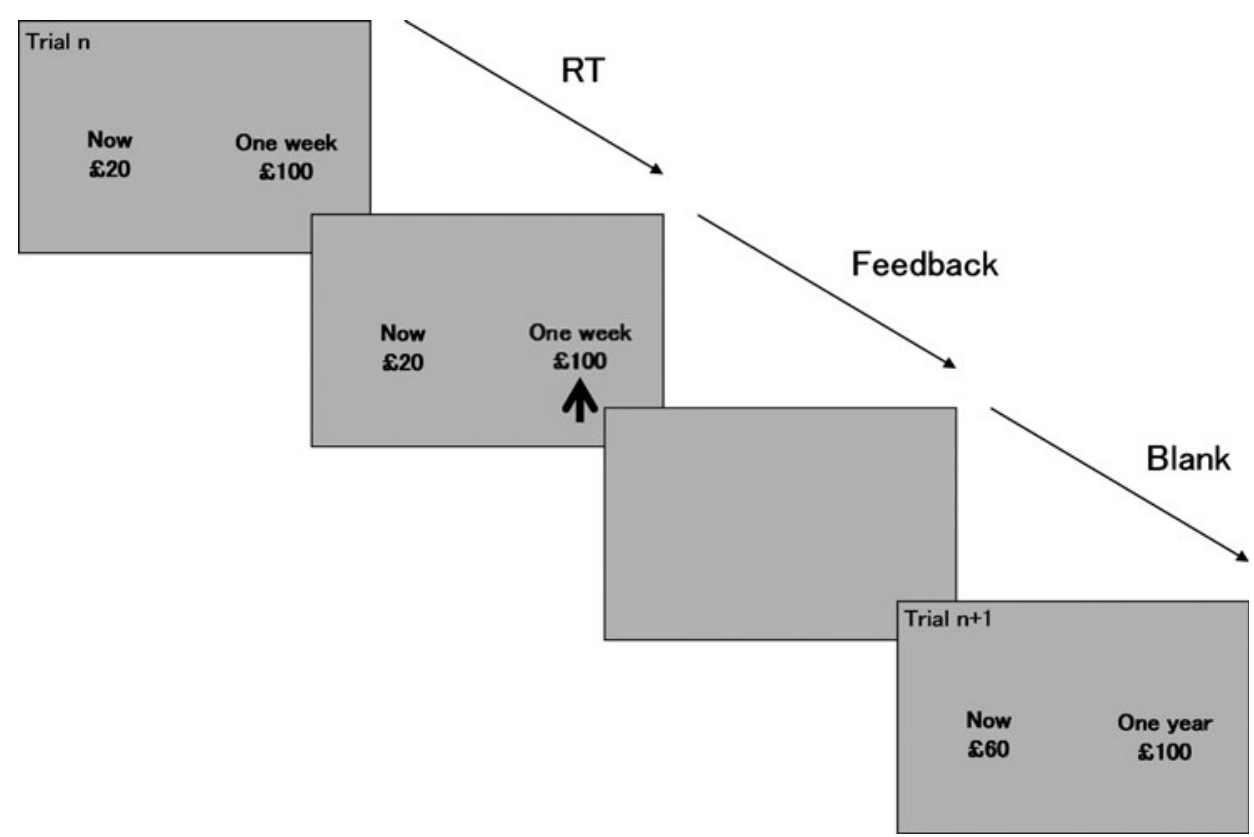

Fig. 1. Schematic of the temporal discounting fMRI paradigm. Subjects are asked to indicate whether they would prefer a small, variable amount of money immediately (immediate reward), or whether they would rather wait for a larger delay (up to $£ 100$ ) later (delayed reward). An algorithm adjusts the amount of the immediate reward offered based on the choices of the participant, so as to determine the lowest immediate reward they would tolerate before instead choosing to wait for the larger delayed reward. Three hypothetical delays are presented in random order: 1 week, 1 month and 1 year. Each delay choice is presented 20 times. Trials start with the presentation of the choice display, which remains available for $4 \mathrm{~s}$, within which the subject must choose between the immediate (always on left side) and delayed (always on right) rewards. Total trial duration is $12 \mathrm{~s}$.

This study was conducted in accordance with the Declaration of Helsinki. Ethical approval was obtained from the local Research Ethics Committee (05/Q0706/ 275). Study details were explained to child and guardian, and written informed consent was obtained for all participants.

\section{TD paradigm}

Prior to scanning, subjects practiced the 12-min TD task (Rubia et al. 2009; Christakou et al. 2011; Chantiluke et al. 2014b) in a mock-scanner. Subjects chose by pressing a left/right button with right index/ middle-finger between receiving a small amount of money immediately ( $£ 0-£ 100)$ or receiving $£ 100$ in 1 week, month or year (Fig. 1). Delays (20 trials each) were randomized, but the delayed option $(£ 100)$ was consistently displayed on the right side of the screen, and variable immediate choices on the left, minimizing sensorimotor mapping effects. Choices were displayed for $4 \mathrm{~s}$, followed by a blank screen of at least $8 \mathrm{~s}$ (inter-trial-interval:12 s). The immediate reward amount was adjusted through an algorithm based on previous choices and calculated separately for each delay. This narrows the range of values, converging on an indifference point where the immediate reward is subjectively considered equivalent to the delayed amount for the given delay (Rubia et al. 2009), ensuring comparable numbers of immediate and delayed choices for analysis.

\section{Analysis of performance data}

To estimate TD steepness for each subject, indifference values between the immediate amount and delayed $£ 100$ for each delay were calculated, equal to the participant's subjective value of $£ 100$ after each delay and defined as the midpoint between the lowest chosen immediate reward and the next lowest immediate reward available (i.e. the value of the immediate reward offered at which point the subject began to choose the delayed reward) (Christakou et al. 2011).

TD was measured using area under the curve (AUC) (Myerson et al. 2001). Smaller AUC denotes steeper discounting rates (i.e. increased choice-impulsivity) (see online Supplement).

One-way between-group analysis of variance (ANOVA) was conducted with AUC as dependent measure to examine group-differences.

\section{fMRI image acquisition}

Gradient-echo echo-planar imaging (EPI) data were acquired at King's College London on a 3T-General 
Electric SIGNA HDx MRI scanner (Milwaukee, WI) using the body coil for radio frequency transmission and a quadrature birdcage head coil for reception. See online Supplement for acquisition parameters. Total scan was $1.5 \mathrm{~h}$ during which subjects completed 2-3 additional fMRI tasks.

\section{fMRI image analysis}

Event-related data were acquired in randomized trial presentation and analysed using the non-parametric XBAM package (v4.1) [www.brainmap.co.uk; (Brammer et al. 1997)]. The individual and group-level analysis methods are described in detail elsewhere (Brammer et al. 1997; Bullmore et al. 1999b; Cubillo et al. 2014) and in the online Supplement.

Briefly, fMRI data were realigned to minimize motion-related artefacts and smoothed using a 7.2 mm full-width-at-half-maximum (FWHM) Gaussian filter (Bullmore et al. 1999a). Time-series analysis of individual activation was performed with a waveletbased resampling method (Bullmore et al. 2001). The main experimental conditions were convolved with 2 Poisson model functions (peaking at 4 and $8 \mathrm{~s}$ ). The weighted sum of these convolutions giving the best fit (least-squares) to the time series at each voxel was calculated. A goodness-of-fit statistic (SSQ ratio) was then computed at each voxel consisting of the ratio of the sum of squares of deviations from the mean intensity value due to the model (fitted time series) divided by that of the squares due to the residuals (original minus model time series). This statistic, the SSQ ratio, was used in further analyses. Individual maps were then normalised to Talairach space (Talairach \& Tournoux, 1988), and a group activation map was produced for each group.

\section{ANCOVA of between-group effects}

One-way between-group analysis of covariance (ANCOVA) with age as covariate was conducted using randomization-based testing to investigate casecontrol differences (Bullmore et al. 1999b, 2001). For these comparisons, statistical thresholds of 0.05 (voxellevel)/0.015 (cluster-level) were selected to obtain $<1$ false-positive 3D cluster per map. Standardized bloodoxygenation level-dependent (BOLD) responses were extracted from significant clusters for each participant and plotted to determine effect direction. Post-hoc significance was determined among pairwise comparisons using a one-way ANOVA.

\section{Influence of behaviour, symptoms and medication}

To examine whether clusters showing significant group effects were related to TD performance or symptoms,
BOLD response from these clusters was extracted for each participant and Spearman correlations (two-tailed) were performed with AUC and symptom subscales within each group. FMRI analyses were also repeated including AUC as covariate.

Lastly, analyses were repeated excluding the four OCD participants prescribed medication.

\section{Results}

\section{Participants}

There were no significant group-differences in age and IQ (Table 1). Multivariate ANOVAs showed groupdifferences on SDQ scores; Post-hoc tests revealed that patients had higher total-scores than controls, with ASD being more impaired than OCD patients (all $p<$ 0.001). On the emotional-distress subscale, both patient groups were more impaired than controls $(p<0.001)$ but did not differ from each other. On all other SDQ subscales, ASD patients were significantly more impaired than controls and OCD patients (all $p<$ 0.005), who did not differ on any measure, with the exception of the conduct subscale where ASD patients differed from controls only $(p<0.001)$.

\section{Performance}

AUC correlated inversely with $k$ (as measured by the square-root transform of these values: $r=-0.555, p<$ 0.001), suggesting adequate congruency between these two metrics. AUC differed between groups [controls: $0.56 \pm 0.13$; ASD: $0.45 \pm 0.24$; OCD: $0.59 \pm 0.15 ; F$ $(2,66)=4.04, p=0.02]$. Post-hoc comparisons showed that ASD patients had significantly smaller AUC compared with controls $(p<0.05)$ and OCD patients $(p<$ $0.01)$, indicating ASD patients discounted rewards more steeply than the other groups, who did not differ from each other.

\section{fMRI data}

\section{Movement}

Multivariate ANOVA showed no group-differences in mean head rotation $[F(2,66)=1.17, p=$ n.s.] or translation $[F(2,66)=2.59, p=$ n.s. $]$ in 3-dimensional Euclidian space.

Group maps of brain activation for delayed-immediate choices

See online Supplement for maps of brain activation within each group for the contrast of delayed-immediate choices (online Supplementary Fig. S1). 
Table 1. Participant characteristics for healthy control boys and patients with OCD or ASD

\begin{tabular}{|c|c|c|c|c|c|}
\hline Variables & $\begin{array}{l}\mathrm{HC}(N=20) \\
\text { Mean (S.D.) }\end{array}$ & $\begin{array}{l}\text { ASD }(N=29) \\
\text { Mean (S.D.) }\end{array}$ & $\begin{array}{l}\text { OCD }(N=20) \\
\text { Mean (S.D.) }\end{array}$ & $F$ test $(\mathrm{df})$ & $p$ value \\
\hline Age (years) & $15.29(1.8)$ & $14.72(1.8)$ & $15.74(1.4)$ & $2.22(2,66)$ & 0.12 \\
\hline IQ & $118.90(11.9)$ & $113.17(13.1)$ & $117.70(13.4)$ & $1.38(2,66)$ & 0.26 \\
\hline SCQ total score & $2.32(2.3)$ & $18.66(8.1)$ & - & $76.98(1,47)$ & $<0.001$ \\
\hline SDQ total score & $5.58(4.2)$ & $19.66(6.8)$ & $12.45(5.6)$ & $35.56(2,66)$ & $<0.001$ \\
\hline SDQ emotional distress subscale & $0.93(1.8)$ & $4.38(2.9)$ & $4.35(2.6)$ & $13.12(2,66)$ & $<0.001$ \\
\hline SDQ conduct subscale & $0.86(1.1)$ & $2.69(2.2)$ & $1.85(1.5)$ & $6.55(2,66)$ & 0.003 \\
\hline SDQ peer relations subscale & $1.53(1.7)$ & $6.59(2.3)$ & $3.30(3.0)$ & $28.72(2,66)$ & $<0.001$ \\
\hline SDQ hyperactive impulsive/inattentive subscale & $2.72(2.4)$ & $5.93(2.6)$ & $2.95(2.7)$ & $12.52(2,66)$ & $<0.001$ \\
\hline SDQ prosocial behaviour subscale & $8.38(2.4)$ & $4.41(2.4)$ & $7.65(2.6)$ & $18.61(2,66)$ & $<0.001$ \\
\hline ADOS communication score & - & $3.62(1.2)$ & - & - & - \\
\hline ADOS social interaction score & - & $9.03(2.3)$ & - & - & - \\
\hline ADOS communication + social & - & $12.66(3.1)$ & - & - & - \\
\hline ADOS stereotypy score & - & $1.52(1.5)$ & - & - & - \\
\hline ADI communication score & - & $16.59(4.7)$ & - & - & - \\
\hline ADI social interaction score & - & $19.97(5.3)$ & - & - & - \\
\hline ADI repetitive behaviour score & - & $6.45(2.4)$ & - & - & - \\
\hline CY-BOCS total score & - & - & $22.33(5.8)$ & - & - \\
\hline CY-BOCS - obsessions & - & - & $10.79(3.6)$ & - & - \\
\hline CY-BOCS - compulsions & - & - & $12.01(3.1)$ & - & - \\
\hline
\end{tabular}

ADI, autism diagnostic interview; ADOS, autism diagnostic observation schedule; ASD, autism spectrum disorder; CY-BOCS, Children's Yale-Brown obsessive-compulsive symptoms checklist; HC, healthy controls; OCD, obsessive-compulsive disorder; SCQ, social communication questionnaire; SDQ, strengths and difficulties questionnaire.

\section{Group-effects on brain activation}

One-way ANOVA showed a significant group-effect for delayed-immediate choices in right ventromedial orbitofrontal cortex (vmOFC) extending into MPFC/ lateral OFC/inferior frontal cortex (IFC), in cerebellum extending into occipital lobe/posterior cingulate (PCC)/ precuneus, in rACC/vmPFC extending into left caudate, in left superior/middle temporal lobe (STL/MTL)/ inferior parietal lobe (IPL) and in right MTL/STL extending into posterior insula/postcentral gyrus/IPL (Fig. 2a; Table 2). ANCOVA including AUC as covariate showed that effects in $\mathrm{rACC} / \mathrm{vmPFC}$ and $\mathrm{PCC} /$ precuneus were related to task performance.

Post-hoc analyses based on extracted SSQs showed that abnormalities in vmOFC/MPFC/IFC were shared between OCD and ASD patients, who had increased activation to immediate-delayed choices relative to controls (both $p<0.001$ ), who had more activation to delayed choices. In cerebellum/occipital lobe/PCC/precuneus, ASD and OCD patients had reduced activation to delayed-immediate choices compared with controls (both $p<0.001$ ). In $\mathrm{rACC} / \mathrm{vmPFC} /$ caudate, both patient groups had decreased activation to immediate-delayed choices relative to controls (ASD: $p<0.001$; OCD: $p<$ $0.05)$, who had enhanced activation to immediatedelayed choices, but this effect was more pronounced in ASD $v$. OCD patients at trend-level $(p<0.1)$. Findings in right MTL/STL/insula/postcentral gyrus/ IPL (all $p<0.005$ ) and left STL/MTL/IPL were due to shared abnormalities in ASD $(p<0.001)$ and OCD $(p<0.005)$ patients, who had less activation to immediate-delayed choices relative to controls who activated this region for immediate $v$. delayed choices (Fig. 2b). When the four OCD patients prescribed medication were excluded from analyses, main findings remained, suggesting medication did not influence task-related activation.

Correlations between differentially activated brain regions and performance

Correlations between areas that differed between groups and AUC showed that greater activation to delayed-immediate choices in cerebellum/occipital lobe/PCC/precuneus was correlated with less-steep TD in the ASD $(r=0.66, p<0.001)$ and OCD groups $(r=0.45, p<0.05)$. Greater activation to immediatedelayed choices in left STL/IPL correlated with lesssteep TD performance in the ASD group $(r=-0.41$, $p<0.05)$. In right MTL/STL/insula/postcentral gyrus/ IPL, it correlated with better TD performance in both $\operatorname{ASD}(r=-0.39, p<0.05)$ and OCD $(r=-0.59, p<0.005)$. 

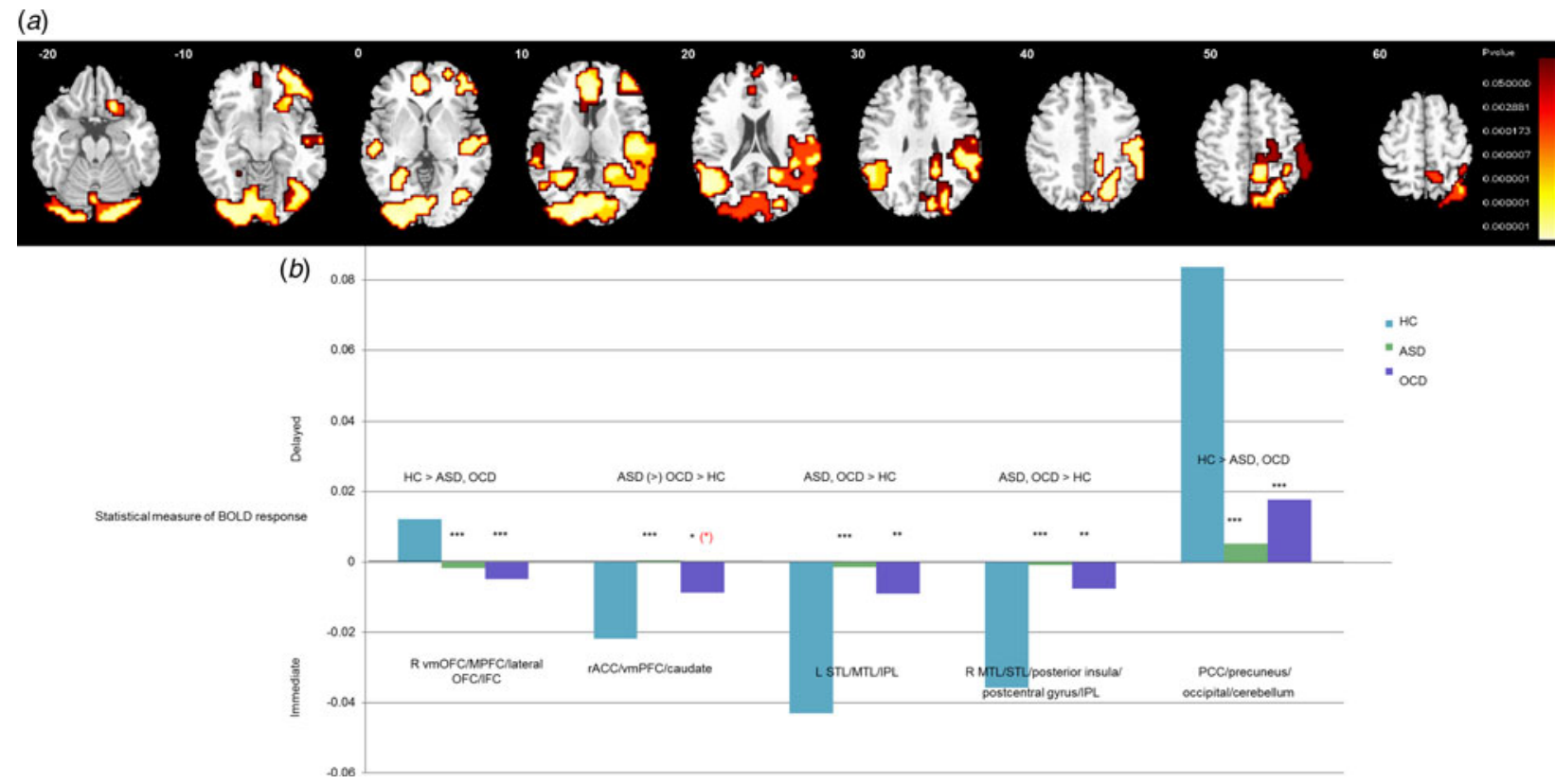

Fig. 2. Between-group activation differences for delayed minus immediate choices. (a) Axial slices showing split-plot analysis of variance (ANOVA) effects of group on brain activation to delayed - immediate choices. Talairach $Z$ coordinates are indicated for slice distance (in $\mathrm{mm}$ ) from the intercommissural line. The right side of the image corresponds to the right side of the brain. (b) Extracted statistical measures of BOLD response are shown for each of the three groups for each of the brain regions that showed a significant group effect. Black asterisks indicate a significant difference between controls and patient group. Red asterisk indicates a difference between the two patient groups. $\left({ }^{*}\right)=$ significant at a trend level; ${ }^{*}=$ significant at the $p<0.05$ level; ${ }^{* *}=$ significant at the $p \leqslant 0.005$ level; ${ }^{* * *}=$ significant at the $p \leqslant 0.001$ level. 
Table 2. Between-group activation differences for delayed minus immediate choices

\begin{tabular}{|c|c|c|c|c|}
\hline Brain regions of activation difference & Brodmann area (BA) & $\begin{array}{l}\text { Peak Talairach } \\
\text { coordinates }(x, y, z)\end{array}$ & Voxels & Cluster $p$ value \\
\hline \multicolumn{5}{|l|}{ (A) $\mathrm{HC}>\mathrm{OCD}$, ASD } \\
\hline $\mathrm{R}$ vmOFC/MPFC/lateral OFC/IFC & $47 / 11 / 25 / 10 / 46$ & $40,56,-13$ & 189 & 0.009 \\
\hline PCC/precuneus/occipital lobe/cerebellum & 31/7/19/18/17 & $-14,-89,4$ & 1060 & 0.0003 \\
\hline \multicolumn{5}{|l|}{ (B) $\mathrm{OCD}, \mathrm{ASD}>\mathrm{HC}$} \\
\hline rACC/vmPFC/left caudate & $10 / 32 / 24$ & $0,41,4$ & 137 & 0.01 \\
\hline L STL/MTL/IPL & 22/39/40/7/19 & $-51,-56,9$ & 273 & 0.005 \\
\hline R MTL/STL/posterior insula/postcentral gyrus/IPL & $22 / 39 / 19 / 5 / 3 / 1 / 2 / 4 / 40 / 7$ & $61,-22,9$ & 654 & 0.001 \\
\hline
\end{tabular}

ASD, autism spectrum disorder; HC, healthy controls; IFC, inferior frontal cortex; IPL, inferior parietal lobe; L, left; MTL, middle temporal lobe; OCD, obsessive-compulsive disorder; OFC, orbitofrontal cortex; R, right; STL, superior temporal lobe; rACC, rostral anterior cingulate cortex; vmOFC, ventromedial orbitofrontal cortex; vmPFC, ventromedial prefrontal cortex.

Correlations between differentially activated brain regions and symptoms

In ASD boys, greater activation to delayed $v$. immediate choices in right vmOFC/MPFC/lateral OFC/IFC correlated at trend-level with lower symptom severity on the repetitive behaviour subscale of the ADI-R $(r=-0.34$, $p=0.07)$. In bilateral STL/insula, lower repetitive behaviour symptom severity was related to increased activation to immediate-delayed choices in the ASD group (left: $r=$ $0.47, p<0.01$; right: $r=0.42, p<0.05$ ). In the OCD group, increased activation to delayed $v$. immediate choices in cerebellum/occipital lobe/PCC/precuneus correlated with lower symptom severity on the CY-BOCS compulsions subscale $(r=-0.58, p<0.01)$. There were no correlations between activation and other subscales from the CY-BOCS in OCD or ADOS/ADI-R in ASD.

\section{Discussion}

This comparison between ASD and OCD adolescents on a 'hot' EF measure of decision-making showed disorder-specific impaired TD in ASD relative to OCD boys and controls. Despite this, patients had predominantly shared neurofunctional deficits in key TD areas including vmOFC/MPFC/IFC, bilateral temporoparietal and cerebellar regions, suggesting that the neural basis of TD is a trans-diagnostic feature of both disorders. In ACC/vmPFC extending into caudate, ASD boys had trend-level more severe underactivation relative to OCD and controls for immediate $v$. delayed choices.

Disorder-specific performance impairment in ASD relative to OCD boys extends previous findings of impairments in ASD during TD (Chantiluke et al. $2014 b$ ), although there have been negative findings (Demurie et al. 2012). The absence of performance differences between OCD boys and controls is in line with previous studies (Vloet et al. 2010; Pinto et al. 2014) [but see (Sohn et al. 2014)]. Moreover, ASD boys had elevated scores on the hyperactive-impulsive/inattention subscale of the SDQ compared with OCD boys and controls. The disorder-specific performance impairment in the ASD group may relate to these elevated impulsivity symptoms observed in ASD but not OCD, given that ADHD patients are consistently impaired in TD (Jackson \& MacKillop, 2016). This finding exclusive to ASD lends support to the distinction between impulsive and compulsive behaviours (Robbins et al. 2012), suggesting that while both disorders exhibit deficits in top-down cognitive control and related circuitry (Dalley et al. 2011), ASD individuals exhibit more impulsive decision-making during TD, as evidenced by disorder-specific impairments and possibly supported by trend-level disorder-specific abnormalities in ACC/vmPFC/caudate, while OCD patients are more habitually compulsive, supported by intact choice behaviour and no disorder-specific abnormalities.

Both patient groups had reduced activation relative to controls to delayed-immediate choices in ventromedial and ventrolateral OFC/IFC. Ventromedial and ventrolateral fronto-limbic regions are key temporal foresight areas (Christakou et al. 2011; Peters \& Büchel, 2011) thought to support calculation of discounted reward value. Moreover, right IFC is a key region for working memory, attention to time and integration of external information with internal value representations, supporting goal-directed EF and mediation of temporal foresight (Wittmann et al. 2007; Rubia et al. 2009; Carlisi et al. 2016a) and has previously been shown to be abnormal during reward-related decision-making in both OCD (Bari \& Robbins, 2013; Stern \& Taylor, 2014) and ASD (Dichter et al. 2012; Kohls et al. 2013).

Both patient groups showed reduced activation in PCC/precuneus/occipital lobe/cerebellum to delayed- 
immediate choices compared with controls. These areas are important parts of fronto-limbic-parietocerebellar networks involved in motivation, reward evaluation and reward response (Vogt et al. 1992; McCoy et al. 2003). The cerebellum is typically activated during delayed choices in healthy populations and has been associated with future outcome expectancy and temporal bridging (Smith et al. 2003; Wittmann et al. 2007, 2010; Rubia et al. 2009; Christakou et al. 2011; Peters \& Büchel, 2011; Noreika et al. 2013). We previously found similar effects in ADHD patients relative to controls during the same task, suggesting that cerebellar underactivation maybe a trans-diagnostic feature of disorders that are challenged in TD (Rubia et al. 2009). Moreover, given the aforementioned role of fronto-limbic-parieto-temporo-cerebellar networks in motivation and reward evaluation, shared abnormalities in this network could possibly relate to neurofunctional similarities in the motivational and reward salience of e.g. performing repetitive behaviours in each disorder, in line with theories of shared impairments in motivation control underpinning these behaviours in each disorder (Hollander et al. 2007). This collectively provides first evidence for shared functional abnormalities in ventromedial and ventrolateral fronto-parieto-striatocerebellar regions between ASD and OCD.

Conversely, relative to controls, both patient groups had reduced activation to immediate choices in the rACC/vmPFC reaching into caudate. However, these abnormalities were at trend-level more pronounced in ASD relative to OCD, possibly linking to ASD-specific performance impairments. rACC mediates decision conflict (Pochon et al. 2008) and typically is increased in activation with decision difficulty during intertemporal choice (Pine et al. 2009). Our recent meta-analysis of structural and functional MRI studies also found shared reductions in this region in ASD and OCD relative to controls both in volume and in activation during cognitive control (Carlisi et al., 2016b). In this study, however, we find that this dysfunction was trend-wise more impaired in ASD, implying a gradual rather than dichotomic effect of more severe impairment in ASD.

Findings of shared reduced vmPFC, left caudate, posterior insula and STL/IPL activation during immediate $v$. delayed choices in patients relative to controls are in line with a wealth of evidence implicating these regions in temporal foresight and reward-based decision-making as well as possible abnormal maturation of networks mediating these processes in ASD and OCD. We showed previously that vmPFC activation to immediate choices during TD increases with age and AUC, indicating an increase in delay-tolerant behaviour linked to increased limbic-corticostriatal activation with age (Christakou et al. 2013a). In children and adults, steeper TD has been associated with an imbalance between reduced activation in ventromedial prefrontal and lateral frontal systems mediating evaluation of future reward and temporal foresight, and reduced top-down control over ventral-striatal and limbic systems, which respond to immediate reward (Christakou et al. 2011; Peters \& Büchel, 2011; Chantiluke et al. 2014b). Moreover, tasks indexing vmPFC functioning have shown age-dependent increases in sensitivity to future consequences (Crone \& van der Molen, 2004) and behavioural control during TD (Steinbeis et al. 2016).

The caudate is involved in time discrimination (Smith et al. 2003), has been linked to reward expectation and evaluation (Hinvest et al. 2011) and is activated during immediate choices in healthy individuals (Christakou et al. 2011). In OCD, OFC-caudate loops are proposed to drive impulsivity as well as compulsive behaviour (Fineberg et al. 2009; Dalley et al. 2011). Thus, results could suggest that adolescents with ASD and OCD both have problems with context-dependent decisionmaking but that this is more problematic for people with ASD, potentially relating to the findings of disorder-specific behavioural deficits in the ASD group. Moreover, the posterior insula is associated with decision-making in the context of prior risk (Xue et al. 2010) and is important for the integration of temporal-affective information (Elliott et al. 2000) and temporal encoding (Wittmann et al. 2010). While previous studies have found specifically anterior insula activation during TD in children (Rubia et al. 2009) and adults (Tanaka et al. 2004; Bickel et al. 2009; Hinvest et al. 2011), the present results highlight a differential abnormality in the posterior insula during reward presentation and internal state evaluation (Elliott et al. 2000) shared between ASD and OCD.

Findings of reduced activation to immediatedelayed choices in STL/IPL in ASD relative to controls are in line with evidence of weaker brain-behaviour correlations in this region in ASD relative to controls during TD (Chantiluke et al. 2014b) and extend these findings to OCD. These regions are important for temporal coding and reward selection (Cardinal, 2006; Christakou et al. 2011), suggesting deficits with planning, consistent with behavioural deficits in this domain in ASD (Hill, 2004) and OCD (Shin et al. 2014). IPL is specifically sensitive to delay (Rubia et al. 1998) and attention-allocation to time (Ortuno et al. 2002; Coull, 2004; Rubia, 2006), as well as duration encoding (Wittmann, 2009) and quantity representation, which may contribute to inter-temporal choices regarding the IPL's role in comparing time and value (Sandrini et al. 2004). Correlations between enhanced activation to immediate choices in the 
patient groups and better TD performance suggest that in both groups, this upregulation is related to a shift in performance towards that of controls, providing possible mechanistic implications of this region in the context of TD behaviour. Moreover, increased activation bilaterally in this region in the ASD group correlated with lower levels of repetitive behaviours, linking performance improvement and symptom reduction to brain activation in these individuals, further highlighting the mechanistic implications of this region in the context of repetitive behaviours and decision-making.

Clinically, the fact that these disorders exhibit shared neural abnormalities during TD has implications for identification of common mechanisms, which may drive overlapping behaviours in each disorder. While symptoms such as compulsions in OCD can sometimes appear similar to repetitive behaviours in ASD at an observational level, less is known about the mechanistic underpinnings of these behaviours and related cognitive functions and whether they are shared or disorder-specific. Thus, this evidence sheds light on trans-diagnostic phenotypes that could aid in future treatment targets and work toward providing a biological explanation of commonalities and differences in clinical behaviour. This has similarly been shown in the case of inhibitory control and brain structure/ function differences/similarities in a recent meta-analysis comparing ASD and OCD (Carlisi et al. 2016b), and this study extends this understanding to temporal foresight and decision-making.

This study's strengths include the thoroughness with which ASD individuals were assessed for the presence of ASD-related symptomatology and the exclusion of patients with psychiatric comorbidities. However, subthreshold symptoms may have been present in the patient samples. The group of ASD patients tested in this study had a relatively high IQ, comparable with that of controls. While matching groups for IQ is important for fMRI studies to disentangle the effects of ASD from the effects of low IQ, this also means that the findings are not generalizable to other more typical ASD patients with low IQ (Charman et al. 2011; Crespi, 2016). The fact that most patients had high-functioning Asperger's syndrome further limits generalizability. Thus, it is possible that OCD-related symptoms were present in the ASD sample and could account for some of the neurobiological overlap in results. In addition, sub-clinical levels of ASD-related symptoms may have been present in the OCD sample, as reflected by shared impairments compared with controls on the emotional-distress SDQ subscale. It would also be interesting to examine the possible effects of puberty on any observed abnormalities. However, it has been shown that impulsive behaviour is independent of puberty in males
(Steinberg et al. 2008). Additionally, four OCD patients were prescribed antidepressant medication. While there is evidence for effects of serotonin on brain function (Murphy et al. 2008; Murphy, 2010), results remained when analyses were repeated excluding these patients. Lastly, It is a common finding that brain activation is more sensitive than performance to detect differences between groups in these patient groups (Fitzgerald et al. 2010; Duerden et al. 2013; Ambrosino et al. 2014; Marsh et al. 2014; Chantiluke et al. 2015b; Morein-Zamir et al. 2015). While the subject numbers have been shown to be sufficient for fMRI analyses (Thirion et al. 2007), the performance and correlation analyses, however, were underpowered.

\section{Conclusions}

This is the first study to compare brain function between these disorders and provides novel evidence to suggest that ASD and OCD share trans-diagnostic abnormalities during TD in ventromedial and ventrolateral fronto-striatal and fronto-temporo-parietocerebellar regions important for temporal foresight and reward-related decision-making. This may drive shared problems with reward-related behaviours and delaying repetitive actions.

\section{Supplementary material}

The supplementary material for this article can be found at https://doi.org/10.1017/S0033291717001088.

\section{Acknowledgements}

This work was supported by grants from the Medical Research Council (MRC G0300155) to K. R. and the MRC UK Autism Imaging Multicentre Study (G0400061) to D. M. This paper represents independent research part-funded by the National Institute for Health Research (NIHR) Biomedical Research Centre at South London and Maudsley NHS Foundation Trust and King's College London. The views expressed are those of the author(s) and not necessarily those of the NHS, the NIHR or the Department of Health. A. C. was supported by a post-doctoral fellowship from MRC G0300155. K.C. and L.N. were supported by Ph.D. studentships from the Institute of Psychiatry, Psychology and Neuroscience, King's College London. C.C. was supported by a NIHR-BRC Ph.D. studentship.

\section{Declaration Interest}

K. R. has received funding from Lilly for another project and speaker's honoraria from Lilly, Shire, Novartis 
and Medice. D. M. has received funding for another project from Lilly. M. B. has served as a consultant for P1Vital. The other authors have no conflict of interests to declare.

\section{Ethical standards}

The authors assert that all procedures contributing to this work comply with the ethical standards of the relevant national and institutional committees on human experimentation and with the Helsinki Declaration of 1975, as revised in 2008 .

\section{References}

Abramovitch A, Abramowitz JS, Mittelman A (2013). The neuropsychology of adult obsessive-compulsive disorder: a meta-analysis. Clinical Psychology Review 33, 1163-1171.

Ambrosino S, Bos D, Van Raalten T, Kobussen N, Van Belle J, Oranje B, Durston S (2014). Functional connectivity during cognitive control in children with autism spectrum disorder: an independent component analysis. Journal of Neural Transmission 121, 1145-1155.

American Psychiatric Association (2013). Diagnostic and Statistical Manual of Mental Disorders, 5th edn. American Psychiatric Publishing: Arlington, VA.

Antrop I, Stock P, Verté S, Wiersema JR, Baeyens D, Roeyers H (2006). ADHD and delay aversion: the influence of non-temporal stimulation on choice for delayed rewards. Journal of Child Psychology and Psychiatry 47, 1152-1158.

Bari A, Robbins TW (2013). Inhibition and impulsivity: behavioral and neural basis of response control. Progress in Neurobiology 108, 44-79.

Benatti B, Dell'osso B, Arici C, Hollander E, Altamura AC (2014). Characterizing impulsivity profile in patients with obsessive-compulsive disorder. International Journal of Psychiatry in Clinical Practice 18, 156-160.

Bickel WK, Pitcock JA, Yi R, Angtuaco EJC (2009). Congruence of BOLD response across intertemporal choice conditions: fictive and real money gains and losses. Journal of Neuroscience 29, 8839-8846.

Blumberg SJ, Bramlett MD, Kogan MD, Schieve LA, Jones JR, Lu MC (2013). Changes in prevalence of parent-reported autism spectrum disorder in school-aged US children: 2007 to 2011-2012. National Health Statistics Reports 65, 1-7.

Brammer MJ, Bullmore ET, Simmons A, Williams SCR, Grasby PM, Howard RJ, Woodruff PWR, Rabe-Hesketh S (1997). Generic brain activation mapping in functional magnetic resonance imaging: a nonparametric approach. Magnetic Resonance Imaging 15, 763-770.

Brem S, Hauser TU, Iannaccone R, Brandeis D, Drechsler R, Walitza $S$ (2012). Neuroimaging of cognitive brain function in paediatric obsessive compulsive disorder: a review of literature and preliminary meta-analysis. Journal of Neural Transmission 119, 1425-1448.
Bullmore E, Brammer M, Rabe-Hesketh S, Curtis V, Morris R, Williams S, Sharma T, Mcguire P (1999a). Methods for diagnosis and treatment of stimulus-correlated motion in generic brain activation studies using fMRI. Human Brain Mapping 7, 38-48.

Bullmore E, Long C, Suckling J, Fadili J, Calvert G, Zelaya F, Carpenter TA, Brammer M (2001). Colored noise and computational inference in neurophysiological (fMRI) time series analysis: resampling methods in time and wavelet domains. Human Brain Mapping 12, 61-78.

Bullmore ET, Suckling J, Overmeyer S, Rabe-Hesketh S, Taylor E, Brammer MJ (1999b). Global, voxel, and cluster tests, by theory and permutation, for a difference between two groups of structural MR images of the brain. IEEE Transactions on Medical Imaging 18, 32-42.

Cardinal RN (2006). Neural systems implicated in delayed and probabilistic reinforcement. Neural Networks 19, 1277-1301.

Carlisi CO, Chantiluke K, Norman L, Christakou A, Barrett N, Giampietro V, Brammer M, Simmons A, Rubia K (2016a). The effects of acute fluoxetine administration on temporal discounting in youth with ADHD. Psychological Medicine 46, 1197-1209.

Carlisi CO, Norman LJ, Lukito SS, Radua J, Mataix-Cols D, Rubia K (2016b). Comparative multimodal meta-analysis of structural and functional brain abnormalities in autism spectrum disorder and obsessive-compulsive disorder. Biological Psychiatry. doi: 10.1016/j.biopsych.2016.10.006.

Chantiluke K, Barrett N, Giampietro V, Brammer M, Simmons A, Murphy DG, Rubia K (2015a). Inverse effect of fluoxetine on medial prefrontal cortex activation during reward reversal in ADHD and autism. Cerebral Cortex 25, 1757-1770.

Chantiluke K, Barrett N, Giampietro V, Brammer M, Simmons A, Rubia K (2014a). Disorder-dissociated effects of fluoxetine on brain function of working memory in attention deficit hyperactivity disorder and autism spectrum disorder. Psychological Medicine 45, 1195-1205.

Chantiluke K, Barrett N, Giampietro V, Santosh P, Brammer M, Simmons A, Murphy D, Rubia K (2015b). Inverse fluoxetine effects on inhibitory brain activation in non-comorbid boys with ADHD and with ASD. Psychopharmacology 232, 2071-2082.

Chantiluke K, Christakou A, Murphy CM, Giampietro V, Daly EM, Brammer M, Murphy DG, Rubia K (2014b). Disorder-specific functional abnormalities during temporal discounting in youth with attention deficit hyperactivity disorder (ADHD), Autism and comorbid ADHD and Autism. Psychiatry Research: Neuroimaging 223, 113-120.

Charman T, Pickles A, Simonoff E, Chandler S, Loucas T, Baird G (2011). IQ in children with autism spectrum disorders: data from the special needs and autism project (SNAP). Psychological Medicine 41, 619-627.

Chen S, Chien Y, Wu C, Shang C, Wu Y, Gau S (2016). Deficits in executive functions among youths with autism spectrum disorders: an age-stratified analysis. Psychological Medicine 46, 1625-1638.

Christakou A, Brammer M, Rubia K (2011). Maturation of limbic corticostriatal activation and connectivity associated 
with developmental changes in temporal discounting. NeuroImage 54, 1344-1354.

Christakou A, Gershman SJ, Niv Y, Simmons A, Brammer M, Rubia K (2013a). Neural and psychological maturation of decision-making in adolescence and young adulthood. Journal of Cognitive Neuroscience 25, 1807-1823.

Christakou A, Murphy C, Chantiluke K, Cubillo A, Smith A, Giampietro V, Daly E, Ecker C, Robertson D, Murphy D (2013b). Disorder-specific functional abnormalities during sustained attention in youth with attention deficit hyperactivity disorder (ADHD) and with Autism. Molecular Psychiatry 18, 236-244.

Coull JT (2004). fMRI studies of temporal attention: allocating attention within, or towards, time. Cognitive Brain Research 21, 216-226.

Crespi BJ (2016). Autism as a disorder of high intelligence. Frontiers in Neuroscience 10, 300. http://doi.org/10.3389/ fnins. 2016.00300

Crone EA, Van Der Molen MW (2004). Developmental changes in real life decision making: performance on a gambling task previously shown to depend on the ventromedial prefrontal cortex. Developmental Neuropsychology 25, 251-279.

Cubillo A, Smith AB, Barrett N, Giampietro V, Brammer MJ, Simmons A, Rubia K (2014). Shared and drug-specific effects of atomoxetine and methylphenidate on inhibitory brain dysfunction in medication-naive ADHD boys. Cerebral Cortex 24, 174-185.

Dalley JW, Everitt BJ, Robbins TW (2011). Impulsivity, compulsivity, and top-down cognitive control. Neuron 69, 680-694.

Demurie E, Roeyers H, Baeyens D, Sonuga-Barke E (2012). Temporal discounting of monetary rewards in children and adolescents with ADHD and autism spectrum disorders. Developmental Science 15, 791-800.

Demurie E, Roeyers H, Baeyens D, Sonuga-Barke E (2013). Domain-general and domain-specific aspects of temporal discounting in children with ADHD and autism spectrum disorders (ASD): a proof of concept study. Research in Developmental Disabilities 34, 1870-1880.

Dichter GS, Richey JA, Rittenberg AM, Sabatino A, Bodfish JW (2012). Reward circuitry function in autism during face anticipation and outcomes. Journal of Autism and Developmental Disorders 42, 147-160.

Di Martino A, Ross K, Uddin LQ, Sklar AB, Castellanos FX, Milham MP (2009). Functional brain correlates of social and nonsocial processes in autism spectrum disorders: an activation likelihood estimation meta-analysis. Biological Psychiatry 65, 63-74.

Doshi-Velez F, Ge Y, Kohane I (2014). Comorbidity clusters in autism spectrum disorders: an electronic health record time-series analysis. Pediatrics 133, e54-e63.

Duerden EG, Taylor MJ, Soorya LV, Wang T, Fan J, Anagnostou E (2013). Neural correlates of inhibition of socially relevant stimuli in adults with autism spectrum disorder. Brain Research 1533, 80-90.

Elliott R, Friston KJ, Dolan RJ (2000). Dissociable neural responses in human reward systems. Journal of Neuroscience 20, 6159-6165.
Figee M, Pattij T, Willuhn I, Luigjes J, Van Den Brink W, Goudriaan A, Potenza MN, Robbins TW, Denys D (2016). Compulsivity in obsessive-compulsive disorder and addictions. European Neuropsychopharmacology 26, 856-868.

Figee M, Vink M, De Geus F, Vulink N, Veltman DJ, Westenberg H, Denys D (2011). Dysfunctional reward circuitry in obsessive-compulsive disorder. Biological Psychiatry 69, 867-874.

Fineberg NA, Potenza MN, Chamberlain SR, Berlin HA, Menzies L, Bechara A, Sahakian BJ, Robbins TW, Bullmore ET, Hollander E (2009). Probing compulsive and impulsive behaviors, from animal models to endophenotypes: a narrative review. Neuropsychopharmacology 35, 591-604.

Fitzgerald KD, Stern ER, Angstadt M, Nicholson-Muth KC, Maynor MR, Welsh RC, Hanna GL, Taylor SF (2010). Altered function and connectivity of the medial frontal cortex in pediatric obsessive-compulsive disorder. Biological Psychiatry 68, 1039-1047.

Geurts HM, Verté S, Oosterlaan J, Roeyers H, Sergeant JA (2004). How specific are executive functioning deficits in attention deficit hyperactivity disorder and autism? Journal of Child Psychology and Psychiatry 45, 836-854.

Gillan CM, Robbins TW (2014). Goal-directed learning and obsessive-compulsive disorder. Philosophical Transactions of the Royal Society B: Biological Sciences 369, 20130475. http:// doi.org/10.1098/rstb.2013.0475.

Goodman R, Scott S (1999). Comparing the strengths and difficulties questionnaire and the child behavior checklist: is small beautiful? Journal of Abnormal Child Psychology 27, $17-24$.

Goodman WK, Price LH, Rasmussen SA, Mazure C, Delgado P, Heninger GR, Charney DS (1989). The yale-brown obsessive compulsive scale: II. validity. Archives of General Psychiatry 46, 1012-1016.

Grassi G, Pallanti S, Righi L, Figee M, Mantione M, Denys D, Piccagliani D, Rossi A, Stratta P (2015). Think twice: impulsivity and decision making in obsessive-compulsive disorder. Journal of Behavioral Addictions 4, 263-272.

Hill EL (2004). Executive dysfunction in autism. Trends in Cognitive Sciences 8, 26-32.

Hinvest NS, Elliott R, Mckie S, Anderson IM (2011). Neural correlates of choice behavior related to impulsivity and venturesomeness. Neuropsychologia 49, 2311-2320.

Hollander E, Kim S, Khanna S, Pallanti S (2007). Obsessive-compulsive disorder and obsessive-compulsive spectrum disorders: diagnostic and dimensional issues. CNS Spectrums 12(S3), 5-13.

Jackson JNS, Mackillop J (2016). Attention-deficit/ hyperactivity disorder and monetary delay discounting: a meta-analysis of case-control studies. Biological Psychiatry: Cognitive Neuroscience and Neuroimaging 1, 316-325.

Just MA, Cherkassky VL, Keller TA, Kana RK, Minshew NJ (2007). Functional and anatomical cortical underconnectivity in autism: evidence from an fmri study of an executive function task and corpus callosum morphometry. Cerebral Cortex 17, 951-961.

Kohls G, Schulte-Rüther M, Nehrkorn B, Müller K, Fink GR, Kamp-Becker I, Herpertz-Dahlmann B, Schultz RT, 
Konrad K (2013). Reward system dysfunction in autism spectrum disorders. Social Cognitive and Affective Neuroscience 8, 565-572.

Kriete T, Noelle DC (2015). Dopamine and the development of executive dysfunction in autism spectrum disorders. PLOS ONE 10, e0121605.

Langen M, Durston S, Kas MJ, Van Engeland H, Staal WG (2011). The neurobiology of repetitive behavior:... and men. Neuroscience and Biobehavioral Reviews 35, 356-365.

Lord C, Risi S, Lambrecht L, Cook Jr. E, Leventhal B, Dilavore P, Pickles A, Rutter M (2000). The autism diagnostic observation schedule - generic: a standard measure of social and communication deficits associated with the spectrum of autism. Journal of Autism and Developmental Disorders 30, 205-223.

Lord C, Rutter M, Couteur A (1994). Autism diagnostic interview-revised: a revised version of a diagnostic interview for caregivers of individuals with possible pervasive developmental disorders. Journal of Autism and Developmental Disorders 24, 659-685.

Marsh R, Horga G, Parashar N, Wang Z, Peterson BS, Simpson HB (2014). Altered activation in fronto-striatal circuits during sequential processing of conflict in unmedicated adults with obsessive-compulsive disorder. Biological Psychiatry 75, 615-622.

Mccoy AN, Crowley JC, Haghighian G, Dean HL, Platt ML (2003). Saccade reward signals in posterior cingulate cortex. Neuron 40, 1031-1040.

Menon V, Uddin LQ (2010). Saliency, switching, attention and control: a network model of insula function. Brain Structure and Function 214, 655-667.

Menzies L, Chamberlain SR, Laird AR, Thelen SM, Sahakian BJ, Bullmore ET (2008). Integrating evidence from neuroimaging and neuropsychological studies of obsessive-compulsive disorder: the orbitofronto-striatal model revisited. Neuroscience and Biobehavioral Reviews 32, 525-549.

Mesulam M-M (1999). Spatial attention and neglect: parietal, frontal and cingulate contributions to the mental representation and attentional targeting of salient extrapersonal events. Philosophical Transactions of the Royal Society of London B: Biological Sciences 354, 1325-1346.

Morein-Zamir S, Voon V, Dodds CM, Sule A, Van Niekerk J, Sahakian BJ, Robbins TW (2015). Divergent subcortical activity for distinct executive functions: stopping and shifting in obsessive compulsive disorder. Psychological Medicine FirstView 1-12.

Murphy CM, Christakou A, Daly EM, Ecker C, Giampietro V, Brammer M, Smith AB, Johnston P, Robertson DM, Consortium MA, Murphy DG, Rubia K (2014). Abnormal functional activation and maturation of fronto-striato-temporal and cerebellar regions during sustained attention in autism spectrum disorder. American Journal of Psychiatry 171, 1107-1116.

Murphy SE (2010). Using functional neuroimaging to investigate the mechanisms of action of selective serotonin reuptake inhibitors (SSRIs). Current Pharmaceutical Design 16, 1990-1997.

Murphy SE, Longhitano C, Ayres RE, Cowen PJ, Harmer CJ, Rogers RD (2008). The role of serotonin in nonnormative risky choice: the effects of tryptophan supplements on the 'reflection effect' in healthy adult volunteers. Journal of Cognitive Neuroscience 21, 1709-1719.

Myerson J, Green L, Warusawitharana M (2001). Area under the curve as a measure of discounting. Journal of the Experimental Analysis of Behavior 76, 235-243.

Noreika V, Falter CM, Rubia K (2013). Timing deficits in attention-deficit/hyperactivity disorder (ADHD): evidence from neurocognitive and neuroimaging studies. Neuropsychologia 51, 235-266.

Norman LJ, Carlisi C, Lukito S, Hart H, Mataix-Cols D, Radua J, Rubia K (2016). Structural and functional brain abnormalities in attention-deficit/hyperactivity disorder and obsessive-compulsive disorder: a comparative meta-analysis. JAMA Psychiatry 73, 815-825.

Odum AL (2011). Delay discounting: trait variable? Behavioural Processes 87, 1-9.

Oldfield RC (1971). The assessment and analysis of handedness: the Edinburgh inventory. Neuropsychologia 9, 97-113.

Ortuno F, Ojeda N, Arbizu J, Lopez P, Marti-Climent J, Penuelas I, Cervera S (2002). Sustained attention in a counting task: normal performance and functional neuroanatomy. NeuroImage 17, 411-420.

Ozonoff S, Jensen J (1999). Brief report: specific executive function profiles in three neurodevelopmental disorders. Journal of Autism and Developmental Disorders 29, 171-177.

Paulus MP, Rogalsky C, Simmons A, Feinstein JS, Stein MB (2003). Increased activation in the right insula during risk-taking decision making is related to harm avoidance and neuroticism. NeuroImage 19, 1439-1448.

Peters J, Büchel C (2010). Episodic future thinking reduces reward delay discounting through an enhancement of prefrontal-mediotemporal interactions. Neuron 66, 138-148.

Peters J, Büchel C (2011). The neural mechanisms of inter-temporal decision-making: understanding variability. Trends in Cognitive Sciences 15, 227-239.

Philip RCM, Dauvermann MR, Whalley HC, Baynham K, Lawrie SM, Stanfield AC (2012). A systematic review and meta-analysis of the fMRI investigation of autism spectrum disorders. Neuroscience and Biobehavioral Reviews 36, 901-942.

Pine A, Seymour B, Roiser JP, Bossaerts P, Friston KJ, Curran HV, Dolan RJ (2009). Encoding of Marginal Utility across Time in the Human Brain. Journal of Neuroscience 29, 9575-9581.

Pinto A, Steinglass JE, Greene AL, Weber EU, Simpson HB (2014). Capacity to delay reward differentiates obsessive-compulsive disorder and obsessive compulsive personality disorder. Biological Psychiatry 75, 653-659.

Pochon J-B, Riis J, Sanfey AG, Nystrom LE, Cohen JD (2008). Functional imaging of decision conflict. Journal of Neuroscience 28, 3468-3473.

Radua J, Pozo NOD, Gómez J, Guillen-Grima F, Ortuño F (2014). Meta-analysis of functional neuroimaging studies indicates that an increase of cognitive difficulty during executive tasks engages brain regions associated with time perception. Neuropsychologia 58, 14-22.

Radua J, Van Den Heuvel OA, Surguladze S, Mataix-Cols D (2010). Meta-analytical comparison of voxel-based 
morphometry studies in obsessive-compulsive disorder vs other anxiety disorders. Archives of General Psychiatry 67, 701-711.

Richards JB, Zhang L, Mitchell SH, Wit H (1999). Delay or probability discounting in a model of impulsive behavior: effect of alcohol. Journal of the Experimental Analysis of Behavior 71, 121-143.

Robbins TW, Gillan CM, Smith DG, De Wit S, Ersche KD (2012). Neurocognitive endophenotypes of impulsivity and compulsivity: towards dimensional psychiatry. Trends in Cognitive Sciences 16, 81-91.

Rubia K (2006). The neural correlates of timing functions. In Timing the Future: the Case for a Time-Based Prospective Memory (ed. J. Glicksohn), pp. 213-238. World Scientific Publishing: Hackensack, NJ.

Rubia K, Halari R, Christakou A, Taylor E (2009). Impulsiveness as a timing disturbance: neurocognitive abnormalities in attention-deficit hyperactivity disorder during temporal processes and normalization with methylphenidate. Philosophical Transactions of the Royal Society B: Biological Sciences 364, 1919-1931.

Rubia K, Overmeyer S, Taylor E, Brammer M, Williams S, Simmons A, Andrew C, Bullmore E (1998). Prefrontal involvement in 'temporal bridging' and timing movement. Neuropsychologia 36, 1283-1293.

Ruscio A, Stein D, Chiu W, KessleR R (2010). The epidemiology of obsessive-compulsive disorder in the National Comorbidity Survey Replication. Molecular Psychiatry 15, 53-63.

Rutter M, Bailey A, Lord C (2003). The Social Communication Questionnaire: Manual. Western Psychological Services: Los Angeles.

Sanders J, Johnson KA, Garavan H, Gill M, Gallagher L (2008). A review of neuropsychological and neuroimaging research in autistic spectrum disorders: attention, inhibition and cognitive flexibility. Research in Autism Spectrum Disorders 2, 1-16.

Sandrini M, Rossini PM, Miniussi C (2004). The differential involvement of inferior parietal lobule in number comparison: a rTMS study. Neuropsychologia 42, 1902-1909.

Schmitz N, Rubia K, Van Amelsvoort T, Daly E, Smith A, Murphy DGM (2008). Neural correlates of reward in autism. British Journal of Psychiatry 192, 19-24.

Scott-Van Zeeland AA, Dapretto M, Ghahremani DG, Poldrack RA, Bookheimer SY (2010). Reward processing in autism. Autism Research 3, 53-67.

Shin NY, Lee TY, Kim E, Kwon JS (2014). Cognitive functioning in obsessive-compulsive disorder: a meta-analysis. Psychological Medicine 44, 1121-1130.

Simonoff E, Pickles A, Charman T, Chandler S, Loucas T, Baird G (2008). Psychiatric disorders in children with autism spectrum disorders: prevalence, comorbidity, and associated factors in a population-derived sample. Journal of the American Academy of Child and Adolescent Psychiatry 47, 921-929.

Singer T, Critchley HD, Preuschoff K (2009). A common role of insula in feelings, empathy and uncertainty. Trends in Cognitive Sciences 13, 334-340.

Smith A, Taylor E, Lidzba K, Rubia K (2003). A right hemispheric frontocerebellar network for time discrimination of several hundreds of milliseconds. NeuroImage 20, 344-350.

Sohn SY, Kang JI, Namkoong K, Kim SJ (2014). Multidimensional measures of impulsivity in obsessive-compulsive disorder: cannot wait and stop. PLoS ONE 9, e111739.

Steinbeis N, Haushofer J, Fehr E, Singer T (2016). Development of behavioral control and associated vmPFCDLPFC connectivity explains children's increased resistance to temptation in intertemporal choice. Cerebral Cortex 26, $32-42$.

Steinberg L, Albert D, Cauffman E, Banich M, Graham S, Woolard J (2008). Age differences in sensation seeking and impulsivity as indexed by behavior and self-report: evidence for a dual systems model. Developmental Psychology 44, 1764-1778.

Stern ER, Taylor SF (2014). Cognitive neuroscience of obsessive-compulsive disorder. Psychiatric Clinics of North America 37, 337-352.

Talairach J, Tournoux P (1988). Coplanar Stereotaxic Atlas of the Human Brain, a 3-dimensional Proportional System: an Approach to Cerebral Imaging. Thieme: New York.

Tanaka SC, Doya K, Okada G, Ueda K, Okamoto Y, Yamawaki S (2004). Prediction of immediate and future rewards differentially recruits cortico-basal ganglia loops. Nature Neuroscience 7, 887-893.

Thirion B, Pinel P, Mériaux S, Roche A, Dehaene S, Poline J-B (2007). Analysis of a large fMRI cohort: statistical and methodological issues for group analyses. NeuroImage 35, 105-120.

Van Den Heuvel OA, Mataix-Cols D, Zwitser G, Cath DC, Van Der Werf YD, Groenewegen HJ, Van Balkom AJLM, Veltman DJ (2011). Common limbic and frontal-striatal disturbances in patients with obsessive compulsive disorder, panic disorder and hypochondriasis. Psychological Medicine 41, 2399-2410.

van den Heuvel OA, Veltman DJ, Groenewegen HJ, Cath DC, van Balkom AJ, van Hartskamp J, Barkhof F, van Dyck R (2005). Frontal-striatal dysfunction during planning in obsessive-compulsive disorder. Archives of General Psychiatry 62, 301-309.

Via E, Radua J, Cardoner N, Happé F, Mataix-Cols D (2011). Meta-analysis of gray matter abnormalities in autism spectrum disorder: should asperger disorder be subsumed under a broader umbrella of autistic spectrum disorder? Archives of General Psychiatry 68, 409-418.

Vloet T, Marx I, Kahraman-Lanzerath B, Zepf F, Herpertz-Dahlmann B, Konrad K (2010). Neurocognitive performance in children with ADHD and OCD. Journal of Abnormal Child Psychology 38, 961-969.

Vogt BA, Finch DM, Olson CR (1992). Functional heterogeneity in cingulate cortex: the anterior executive and posterior evaluative regions. Cerebral Cortex 2, 435-443.

Voon V, Derbyshire K, Ruck C, Irvine MA, Worbe Y, Enander J, Schreiber LRN, Gillan C, Fineberg NA, Sahakian BJ, Robbins TW, Harrison NA, Wood J, Daw ND, Dayan P, Grant JE, Bullmore ET (2015). Disorders of compulsivity: a common bias towards learning habits. Molecular Psychiatry 20, 345-352. 
Wechsler D (1999). Wechsler Abbreviated Scale of Intelligence. Psychological Corporation: San Antonio, TX.

Wesley MJ, Bickel WK (2014). Remember the future II: meta-analyses and functional overlap of working memory and delay discounting. Biological Psychiatry 75, 435-448.

WHO (1992). The ICD-10 Classification of Mental and Behavioural Disorders: Clinical Descriptions and Diagnostic Guidelines. World Health Organization: Geneva.

Wiener M, Turkeltaub P, Coslett HB (2010). The image of time: a voxel-wise meta-analysis. Neurolmage 49, 1728-1740.

Wittmann M (2009). The inner experience of time. Philosophical Transactions of the Royal Society of London B: Biological Sciences 364, 1955-1967.
Wittmann M, Leland DS, Paulus MP (2007). Time and decision making: differential contribution of the posterior insular cortex and the striatum during a delay discounting task. Experimental Brain Research 179, 643-653.

Wittmann M, Simmons AN, Aron JL, Paulus MP (2010). Accumulation of neural activity in the posterior insula encodes the passage of time. Neuropsychologia 48, 3110-3120.

Xue G, Lu Z, Levin IP, Bechara A (2010). The impact of prior risk experiences on subsequent risky decision-making: the role of the insula. NeuroImage 50, 709-716.

Zelazo PD, Müller U (2007). Executive function in typical and atypical development. In Blackwell Handbook of Childhood Cognitive Development (ed. U. Goswami), pp. 445-469. Blackwell Publishers Ltd: Malden, MA. 